\title{
Multiparentalidade e os efeitos jurídicos do seu reconhecimento
}

\author{
Multiparentality and the legal effects of its recognition \\ Multiparentalidad y efectos legales de su reconocimento
}

Recebido: 28/06/2021 | Revisado: 04/07/2021 | Aceito: 09/07/2021 | Publicado: 20/07/2021

\author{
Daniele Melo da Costa Silva \\ ORCID: https://orcid.org/0000-0001-9330-0894 \\ Christus Faculdade do Piauí, Brasil \\ E-mail: danielemelocs@gmail.com \\ Maria Fernanda Gonçalves de Brito \\ ORCID: https://orcid.org/0000-0001-5769-1955 \\ Christus Faculdade do Piauí, Brasil \\ E-mail: mariafernandagoncalvesbrito@gmail.com \\ Ivonalda Brito de Almeida Morais \\ ORCID: https://orcid.org/0000-0002-1306-7568 \\ Christus Faculdade do Piauí, Brasil \\ E-mail: ivonaldaa@yahoo.com.br \\ Genyvana Criscya Garcia Carvalho \\ ORCID: https://orcid.org/0000-0002-8151-8746 \\ Christus Faculdade do Piauí, Brasil \\ E-mail: genyvanacarvalho@chrisfapi.com.br
}

\begin{abstract}
Resumo
O presente estudo versa sobre a Multiparentalidade e os efeitos jurídicos do seu reconhecimento e apresenta como questão norteadora: “Quais os efeitos jurídicos advindos do reconhecimento da multiparentalidade?". A pesquisa tem o escopo de compreender as repercussões jurídicas oriundas do referido instituto e tem como objetivos específicos: discutir a filiação no direito brasileiro, apontar os princípios que regem o direito de família, analisar as disposições gerais que versam sobre a multiparentalidade, bem como investigar suas repercussões jurídicas. Utilizou-se a pesquisa bibliográfica, com pesquisa em livros e legislação vigente, além de artigos buscados nas principais bases de dados, como Google Acadêmico e Scielo, tendo como descritores as palavras: multiparentalidade, paternidade e efeitos jurídicos. Os principais autores utilizados foram Cristiano Chaves de Farias e Nelson Rosenvald, Maria Berenice Dias, Conrado Paulino da Rosa e Flávio Tartuce. Utilizou-se ainda a pesquisa documental, com a análise de julgados que possibilitou uma compreensão pormenorizada do instituto em comento, haja vista que a Tese de Repercussão Geral $n^{\circ}$ 622, firmada pelo Supremo Tribunal Federal, deixou claro que não há hierarquia entre as paternidades biológica e socioafetiva e que ambas podem existir, simultaneamente, gerando efeitos jurídicos próprios, restando claro que a referida tese gera diversas repercussões jurídicas, dentre as quais podem ser citadas o direito ao nome, alimentos, guarda/visita e direitos sucessórios. Enfim, são diversas as consequências oriundas do entendimento dos tribunais pátrios, importando mencionar que a doutrina tem desempenhado papel de destaque na interpretação de tais efeitos jurídicos, vez que se trata de um tema recente e que não há regramento próprio para regulamentar especificamente cada caso.
\end{abstract}

Palavras-chave: Paternidade; Multiparentalidade; Efeitos jurídicos.

\begin{abstract}
This study deals with Multiparenthood and the legal effects of its recognition and presents as a guiding question: "What are the legal effects arising from the recognition of multiparenting?". The research has the scope of understanding the legal repercussions arising from the referred institute and has as specific objectives: to discuss the affiliation in Brazilian law, to point out the principles that govern family law, to analyze the general provisions that deal with multiparenting, as well as to investigate its legal repercussions. Bibliographic research was used, with research in books and current legislation, in addition to articles searched in the main databases, such as Google Academic and Scielo, with the words: multiparenthood, paternity and legal effects as descriptors. The main authors used were Cristiano Chaves de Farias and Nelson Rosenvald, Maria Berenice Dias, Conrado Paulino da Rosa and Flávio Tartuce. Documentary research was also used, with the analysis of judgments that allowed a detailed understanding of the institute under discussion, given that the General Repercussion Thesis No. 622, signed by the Federal Supreme Court, made it clear that there is no hierarchy between the biological paternity and socio-affective and that both can exist, simultaneously, generating their own legal effects, leaving it clear that the referred thesis generates several legal repercussions, among which the right to name, alimony, custody/visit and inheritance rights can be cited. Finally, there are several consequences arising from the understanding of the Brazilian courts, it is worth
\end{abstract}


mentioning that the doctrine has played a prominent role in the interpretation of such legal effects, since this is a recent issue and there is no specific rule to specifically regulate each case.

Keywords: Paternity; Multiparenting; Legal effects.

\section{Resumen}

Este estudio trata sobre la multiparentidad y los efectos legales de su reconocimiento y presenta como pregunta orientadora: “¿Cuáles son los efectos legales derivados del reconocimiento de la multiparentidad?”. La investigación tiene el alcance de comprender las repercusiones jurídicas derivadas del referido instituto y tiene como objetivos específicos: discutir la afiliación en el derecho brasileño, señalar los principios que rigen el derecho de familia, analizar las disposiciones generales que tratan de la multiparentidad, como así como investigar sus repercusiones legales. Se utilizó investigación bibliográfica, con búsqueda en libros y legislación vigente, además de artículos buscados en las principales bases de datos, como Google Academic y Scielo, con las palabras: multiparentidad, paternidad y efectos legales como descriptores. Los principales autores utilizados fueron Cristiano Chaves de Farias y Nelson Rosenvald, Maria Berenice Dias, Conrado Paulino da Rosa y Flávio Tartuce. También se utilizó la investigación documental, con el análisis de sentencias que permitieron un conocimiento detallado del instituto en discusión, dado que la Tesis de Repercusión General No. 622, suscrita por el Supremo Tribunal Federal, dejó claro que no existe jerarquía entre lo biológico paternidad y socioafectiva y que ambos pueden existir, simultáneamente, generando sus propios efectos jurídicos, dejando claro que la tesis referida genera varias repercusiones legales, entre las que se pueden citar el derecho a nombre, pensión alimenticia, custodia /visita y herencia. Finalmente, existen varias consecuencias derivadas del entendimiento de los tribunales brasileños, cabe mencionar que la doctrina ha jugado un papel destacado en la interpretación de tales efectos jurídicos, ya que este es un tema reciente y no existe una norma específica que regule especificamente cada caso.

Palabras clave: Paternidad; Multiparentidad; Efectos legales.

\section{Introdução}

Até pouco tempo, consideravam-se três critérios para a determinação da filiação (biológico, presunção legal e socioafetivo), sendo que um deles deveria prevalecer (Farias \& Rosenvald, 2018). Ademais, ainda dever-se-ia observar o Enunciado 339 do CJF/STJ, que aduzia: “A paternidade socioafetiva, calcada na vontade livre, não pode ser rompida em detrimento do melhor interesse do filho".

Até que em 2016, o Supremo Tribunal Federal, numa decisão inédita, de repercussão geral, fixou uma nova tese jurídica na qual restou claro que não há qualquer tipo de hierarquia entre a paternidade biológica e socioafetiva. Dessa maneira, é plenamente viável o posterior reconhecimento de um ou outro tipo de filiação, seja aquela oriunda dos laços sanguíneos, seja a decorrente dos vínculos de afetividade (Recurso Extraordinário 898.060 SC de 22 de setembro, 2016).

A partir de então, ficou cada vez mais comum o reconhecimento simultâneo de dois pais ou duas mães para uma mesma pessoa, consolidando-se o instituto da multiparentalidade ou pluriparentalidade, produzindo-se feitos jurídicos em relação a todos (Farias \& Rosenvald, 2018).

Para Gonçalves (2017), o referido instituto consiste na possibilidade do direito reconhecer dois pais ou mães, um biológico e outro socioafetivo, valorizando-se a filiação oriunda do afeto. Diante de tal acepção resta comprovado que o vínculo afetivo hoje é tão importante quantos os laços sanguíneos, sendo que tal situação vem cada vez mais ganhando repercussão no meio doutrinário e jurisprudencial.

Dessa forma, o presente estudo versa sobre a Multiparentalidade, ficando assim delimitado: Multiparentalidade e os efeitos jurídicos do seu reconhecimento. Possui como questão norteadora: "Quais os efeitos jurídicos advindos do reconhecimento da Multiparentalidade?".

A pesquisa visa compreender os efeitos do referido instituto, possuindo como objetivos específicos: discutir a filiação no direito brasileiro, apontar os princípios que regem o direito de família, analisar as disposições gerais que versam sobre a multiparentalidade e investigar suas repercussões jurídicas.

A investigação e compreensão do instituto da multiparentalidade tornam-se bastante relevantes devido à constante variação dos modelos familiares na contemporaneidade, de forma que houve vasta mutabilidade no Direito de Família 
brasileiro em função da alteração dos valores e comportamentos da sociedade. A família antes ligada somente por laços consanguíneos, agora passou a ser reconhecida por laços de afetividade, o que amplia significativamente o rol de possibilidade de núcleos parentais.

\section{Metodologia}

O presente estudo refere-se à análise pormenorizada do instituto da multiparentalidade, em relação ao seu reconhecimento, aplicabilidade no caso concreto e, especialmente, com ênfase no que concerne aos seus efeitos jurídicos. Assim, para melhor compreensão do tema, foi realizada pesquisa bibliográfica, observando-se livros, artigos, julgados, dentre outros materiais que versam sobre o objeto em comento.

A pesquisa bibliográfica consiste em uma produção que está voltada para livros, revistas, resumos, artigos científicos, dentre tantas outras possibilidades. É importante destacar que, na atualidade, os artigos constituem-se uma importante fonte de conhecimento haja vista que neles podem ser encontrados o que há de mais atualizado sobre o assunto, constituindo-se como o primeiro foco de pesquisa (Marconi \& Lakatos, 2019).

É imprescindível, em qualquer estudo, possibilitar aqueles que terão contato com a matéria uma aproximação e, quem sabe, até mesmo uma afinidade com o que está sendo explorado, por meio de informações que partem desde os pontos gerais até as especificidades do tema. Logo, a análise bibliográfica mostrou-se como uma excelente fonte de informações, razão esta pela qual foi adotada.

Um dos principais benefícios é que ela possibilita uma análise ampla e pormenorizada, o que muitas vezes seria inviável quando a problemática levantada exige a coleta de dados dispersos no meio físico. Além do mais, permite ainda o conhecimento de fatos pretéritos que constituem importantes fontes históricas, imprescindíveis à compreensão do conteúdo exposto (Gil, 2010).

Foi ainda realizada pesquisa documental, que por vezes se confunde com a pesquisa bibliográfica, mas se diferencia da última devido ao tipo de material utilizado, uma vez que a pesquisa bibliográfica se baseia na análise de materiais elaborados com o propósito de serem lidos por um público específico, enquanto a pesquisa documental fundamenta-se na vistoria de documentos que foram produzidos com finalidades diversas, como assentamento, autorização ou comunicação (Gil, 2010). Dessa maneira, foram analisados documentos tais como sentenças, acórdãos, provimentos, dentre outros que possibilitam a compreensão sobre tema abordado.

Tendo em vista essas considerações, pode-se perceber que há muito o que ser explorado, por meio da pesquisa bibliográfica, uma vez que esta dispõe de mecanismos eficazes e aptos a propiciarem uma gama de informações de alta qualidade que se tornam imprescindíveis para a compreensão do estudo.

\section{Resultados e Discussão}

\subsection{O direito de família no sistema jurídico brasileiro}

No processo de formação da família ao longo dos tempos, houve grande influência das civilizações greco-romanas, bem como dos ditames da religião, fator derivado principalmente da influência do cristianismo (Rosa, 2020).

$\mathrm{Na}$ Roma Antiga, a entidade familiar era marcada pelo poder patriarcal, uma vez que todos os membros do grupo deveriam estar subordinados ao chefe da família, também denominado como pater famílias (Noronha \& Parron, 2012). Ademais, o resultado precípuo do casamento era a união de duas pessoas a fim de formar um culto doméstico e perpetuá-lo, de forma que, uma vez formada a família, não havia a possibilidade de extinção, independentemente da existência ou não de afeto entre seus membros (Rosa, 2020).

Com a queda do Império Romano e a ascensão do Cristianismo, apesar de manter o patriarcalismo, a família passou a 
ter um novo significado, pois passou a funcionar como uma extensão da Igreja que, por sua vez, se confundia com o Estado (Gagliano \& Filho, 2019). Nessa época já existia uma breve preocupação com o afeto, uma vez que deveria haver, ao menos em tese, o consentimento dos nubentes.

O Código Civil Brasileiro de 1916 ainda demonstrava nitidamente as origens patriarcais das sociedades antigas, visto continuar a estabelecer a figura do homem como o chefe da família, conforme pode ser demonstrado com a leitura de alguns de seus artigos e "[...] por sua vez, não abriu qualquer espaço para outras formas de organização familiar que não aquela decorrente do casamento [...]” (Xavier, 2015, p. 28).

Ulteriormente, a Constituição Federal de 1988 significou uma verdadeira reviravolta no que tange ao direito de família, pois seus preceitos afrontavam diretamente o modelo familiar estabelecido no Código Civil de 1916, de forma a alterar significativamente, na perspectiva jurídica, o cenário do ambiente doméstico (Schreiber, 2020). Dessa forma, as modificações trazidas pela Constituição de 1988 tiveram grande reflexo no Código Civil de 2002, uma vez que as demais normas deveriam estar submetidas à Lei Maior.

Posto isso, hodiernamente há a valorização do afeto, uma vez que a pessoa humana só pode exercer sua dignidade de forma plena quando não é impedida de demonstrar seus sentimentos e emoções. Nesse sentido, o artigo 1593 do Código Civil de 2002 preceitua que "O parentesco é natural ou civil, conforme resulte de consanguinidade ou outra origem". Do mesmo modo, o artigo 1596 do mesmo diploma legal preceitua que não se fará qualquer discriminação em relação aos filhos de diferentes origens, sendo resguardado a todos os mesmos direitos e qualificações.

Nesse contexto, é válido salientar a relação de parentesco que, para Tartuce (2020), seria determinado como o vínculo jurídico entre pessoas que possuem a mesma origem genética, bem como aquelas que têm entre si um vínculo civil, sendo a filiação, por sua vez, a relação de parentesco existente entre pais e filhos.

De acordo com Rosa (2020), a filiação pode ser dividida em quatro tipos: a) filiação matrimonial, ou seja, aquela que ocorre na constância do casamento, e em que reina a presunção de paternidade; b) filiação decorrente de relacionamento convivencial ou eventual, proveniente da relação de união estável e relacionamentos eventuais, como namoros e encontros casuais; c) filiação decorrente de procedimento de reprodução assistida; c) filiação socioafetiva por meio da posse do estado de filho.

No que tange a este último tipo de filiação, trata-se de um desdobramento da teoria da aparência, pois leva em consideração aquilo que é visível, ou seja, se uma entidade familiar é formada por pessoas que se comportam como pais e outras que se comportam como filhos não há como distinguir se a filiação é biológica ou socioafetiva (Rosa, 2020). Dessa forma, aquilo que é contemplado pela sociedade e ocorre de forma contínua na realidade do agrupamento familiar é relevante para constituir uma relação de filiação, visto que o afeto está ocupando um espaço de grande importância no ordenamento jurídico brasileiro.

Para Tartuce (2020), a caracterização da posse do estado de filho é realizada por meio do preenchimento de alguns critérios. O primeiro deles é Tractatus ou Tractatio, referente ao tratamento das partes perante a sociedade, ou seja, estas devem se relacionar como pais e filhos. O segundo critério é a Reputatio, ou seja, a fama, a repercussão do tratamento supracitado, de forma que a sociedade reconheça as partes envolvidas como pais e filhos. Por fim, tem-se o Nomen ou Nominatio, presente na situação em que o declarado filho utiliza o sobrenome do suposto pai. Vale salientar que não será analisado somente o nome registral civil, mas também o nome socialmente utilizado. No entanto, segundo Rosa (2020), o critério que se refere ao nome é facultativo, uma vez que a socioafetividade pode ocorrer mesmo quando a pessoa não utiliza o sobrenome da família que o criou como filho. 


\subsection{Princípios que regem o direito de família}

Segundo Dias (2021), a ausência de leis sobre determinado assunto não implica dizer que aquele direito não existe. $O$ magistrado não pode ficar adstrito unicamente ao legislador, pois ele tem por função analisar o caso e garantir o amparo jurídico, devendo dar-lhe uma solução, embora não haja disposição legal relativa à situação específica.

No que tange à Multiparentalidade, os princípios desempenham um papel de grande valia, visto que na inexistência de disposição legal, servem como base para nortear as decisões e resolver os impasses que chegam ao Poder Judiciário. Desse modo, na seara familiarista destacam-se vários princípios, dentre os quais podem ser citados: Dignidade da pessoa humana, Função social, Pluralidade das entidades familiares, Melhor interesse da criança e do adolescente e Afetividade (Figura 1).

O princípio da Dignidade da pessoa humana encontra fulcro no art. $1^{\circ}$, inciso III da Carta Magna, e de acordo com Gagliano e Filho (2017) possui fundamento na própria existência do homem. Ademais, segundo afirma Tartuce (2020), o referido princípio tem ampla acepção. Dessa forma, podem ser extraídas diferentes interpretações. A Função social da família, por sua vez, contempla um sentimento humanitário de cooperação, auxílio e apoio mútuos. Segundo Farias e Rosenvald (2017), pode ser evidenciada tanto na condenação ao pagamento de alimentos para possibilitar a mantença dos membros da família, bem como no reconhecimento da união estável quando, embora não haja o divórcio, esteja caracterizada a separação de fato.

O princípio da Pluralidade das entidades familiares decorre das mudanças sociais relativas ao conceito de família na contemporaneidade. De maneira que, conforme o art. 226 da Constituição Federal, passou a receber proteção estatal não só a família oriunda do casamento, mas também a união estável e a família monoparental, sendo importante salientar ainda, que o rol constitucional não é taxativo, podendo englobar outras entidades familiares. Em relação ao princípio do Melhor interesse da criança e do adolescente, Farias e Rosenvald (2017) dizem que, quando necessário, os pais devem deixar de lado seus próprios interesses a fim de garantir o melhor para a criança ou adolescente. Nessa perspectiva, deve-se sempre fazer uma análise minunciosa das questões envolvidas para, só então, eleger a mais conveniente à tutela dos direitos infantojuvenis.

Por fim, e não menos importante, o princípio da Afetividade, conforme Pereira (2016), é um princípio constitucional pertencente à classe daqueles não expressos, de forma que está respaldado na própria Constituição Federal, mesmo que subentendido. Ademais, segundo Dias (2021), tal princípio possibilita a paridade entre irmãos biológicos e adotivos, sendo este um dos fundamentos basilares da entidade familiar.

Diante do exposto, apresenta-se o seguinte esquema com os princípios estudados.

Figura1 - Princípios do Direito de Família.

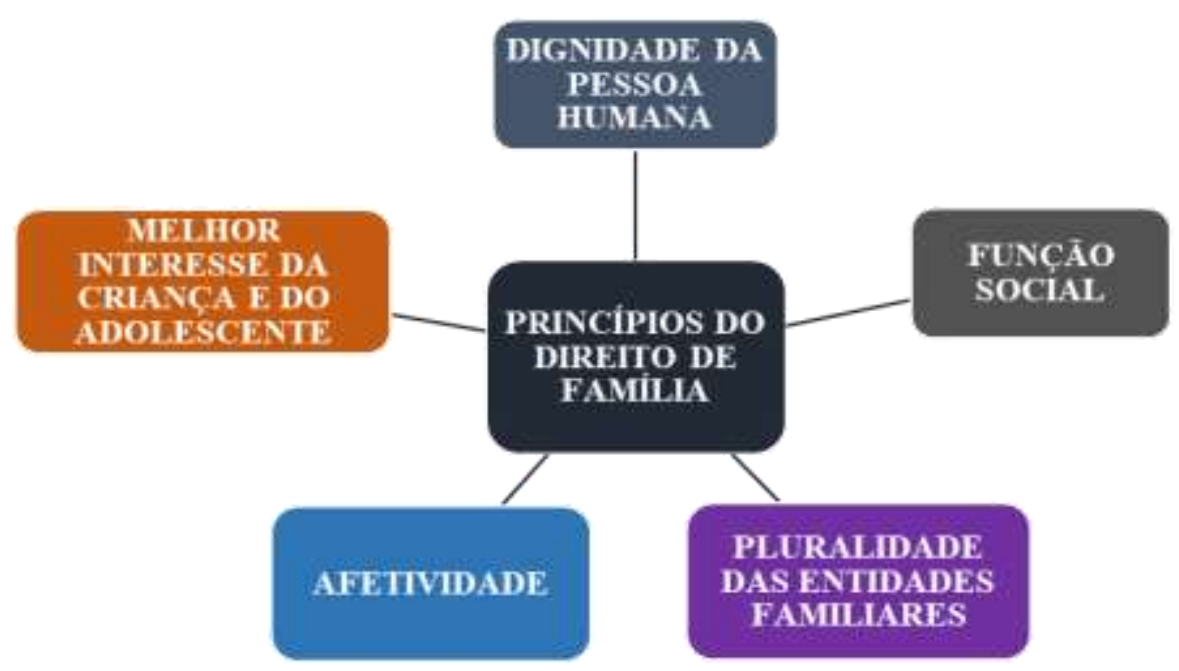

Fonte: Sistematizado pelas autoras. 
Dessarte, é cediço afirmar que o Direito de família utiliza os princípios de modo a orientar o aplicador do direito nessa árdua tarefa de manter a equidade e o senso de justiça. De mais a mais, o direito não pode ficar alheio aos fatos novos em decorrência da ausência de leis específicas a serem aplicadas em cada situação.

\subsection{Disposições gerais sobre a multiparentalidade}

No contexto da valorização do afeto dentro das relações familiares associado à evolução do direito de família, com significativa ampliação dos modelos familiares, torna propício o nascimento, discussão e aperfeiçoamento de institutos como o da Multiparentalidade, reconhecida como a situação fática em que um filho possui dupla paternidade ou maternidade. Dito isto, é indubitável afirmar que o Supremo Tribunal Federal deu uma nova perspectiva ao Direito de Família, quando passou a admitir expressamente a possibilidade jurídica de reconhecimento da pluriparentalidade, ao firmar a tese de repercussão geral $n^{\circ} 622$.

Segundo Calderón (2018), o caso concreto que orientou a decisão do STF, ocorreu no Estado de Santa Catarina, na qual uma filha, que continha um pai registral, com mais de 18 anos de convívio, descobriu que ele não era seu pai biológico. Diante dos fatos, ela resolveu ajuizar uma ação com objetivo de "excluir" a paternidade registral, a fim de constar em seu assento de nascimento o nome do pai biológico, visto que até então só havia possibilidade de reconhecer um pai. A defesa deste, afirmava que a jovem já era maior de idade e tal postulação tinha fins meramente patrimoniais. Alegou ainda, que durante todo aquele período ela teve um pai socioafetivo, devidamente registrado, e não seria possível declarar uma segunda paternidade, devendo a parentalidade socioafetiva prevalecer em detrimento da biológica, importando assim, em indeferimento do pleito autoral.

Consequentemente, o Supremo Tribunal Federal, em análise do Recurso Extraordinário nº 898.060, por maioria, fixou a tese de repercussão geral $n^{\circ} 622$, na qual ficou estabelecido que "A paternidade socioafetiva, declarada ou não em registro público, não impede o reconhecimento do vínculo de filiação concomitante baseado na origem biológica, com os efeitos jurídicos próprios".

Desse modo, sem excluir a paternidade já existente, pautada nos laços afetivos, acolheu-se a parentalidade biológica, com todos os efeitos jurídicos naturais à filiação, figurando assim, no caso em comento, dois pais. Diante disso, foi aprovada a tese supramencionada, com efeito vinculante, que servirá como parâmetro em situações similares (Calderón, 2018).

Ademais, a multiparentalidade tornou-se um inevitável no atual Direito de Família. Ela passou a ser a regra quando houver impasse entre a parentalidade socioafetiva e a biológica. Logo, a tese firmada em repercussão geral deu fim à discussão (Tartuce, 2020).

Insta salientar ainda que, segundo Calderón (2018), um dos fundamentos do voto do Ministro Luiz Fux foi o Direito da busca à felicidade, que se consagra no ordenamento pátrio por meio do Princípio da dignidade da pessoa humana. Ademais, a afetividade também ganhou destaque na Corte, vez que vários ministros fizeram menção à ela, conferindo-lhe valor jurídico.

Destaque-se que o Tribunal de Justiça do Estado do Piauí, em sede de recurso (apelação cível n. 2015.0001.0027537), já apreciou um processo oriundo da $2^{\mathrm{a}}$ Vara da Comarca de Piripiri-PI, invocando em sua ementa a Tese de Repercussão Geral n 622 do Supremo Tribunal Federal:

PROCESSO CIVIL-APELAÇÃO - ANULATÓRIA DE REGISTRO CIVIL- INÉPCIA DA APELAÇÃO- INC. II, DO ART. 514, DO CPC/73- FÁCIL COMPREENSÃO DOS FUNDAMENTOS DE FATO E DE DIREITO DA IRRESIGNAÇÃO RECURSAL- PRELIMINAR REJEITADA- MÉRITO- EVIDENCIAS AFETIVAS NO HISTÓRICO FAMILIAR- RECONHECIMENTO DOS VÍNCULOS DE PARENTESCOS BIOLÓGICO E SOCIOAFETIVO- POSSIBILIDADE- RECURSO NÃO PROVIDO.

1. Não há inépcia da apelação quando facilmente compreendidos os fundamentos de fato e de direito da irresignação recursal. 
2. O Supremo Tribunal Federal, por ocasião de julgamento de mérito, em sede de repercussão geral do Recurso Extraordinário n. 898060, acatou a proposta de "pluriparentalidade", a qual defende a ideia de "dupla paternidade", quando verificado, por óbvio, histórico familiar afetivo, fundando-se, para tanto, no princípio da dignidade da pessoa humana, tudo no afã de tutelar, jurídica e de forma concomitante, os vínculos de parentesco biológicos e socioafetivos.

3. Sentença mantida à unanimidade.

(TJPI | Apelação Cível No 2015.0001.002753-7 | Relator: Des. Raimundo Nonato da Costa Alencar | $4^{\mathrm{a}}$ Câmara Especializada Cível | Data de Julgamento: 14/08/2018)

O caso em comento refere-se à Ação Anulatória de Paternidade, cujo requerente ingressou em face da menor S.R.S.M, no ato, representada por sua genitora. O proponente alegava que durante o término de um relacionamento 12 (doze) anos de duração com a companheira, esta informou que estava grávida. Assim, o peticionário, de forma voluntária e espontânea, reconheceu a criança por acreditar que esta era sua filha biológica, e passou a tratá-la como tal, oferecendo-lhe todo suporte necessário ao seu desenvolvimento, tanto material, quanto afetivo. Em eventos sociais, o proponente sempre era visto na companhia da criança e da genitora, e ao chegar à idade escolar passou a levar e buscar a criança na escola constantemente, com muito carinho.

No entanto, após a realização de um exame hematológico de D.N.A, em que foi colhido o material genético de um terceiro e da requerida, restou demonstrado que estes eram pai e filha. Dessa maneira, por meio da realização do referido exame, foi comprovado que o requerente e a infante não compartilhavam nenhum vínculo genético, motivo pelo qual foi proposta a supracitada ação.

Ocorre que, posteriormente ao ajuizamento da ação, o requerente veio a falecer em decorrência de acidente automobilístico, de maneira que, seus genitores habilitaram-se no processo na condição de sucessores processuais. Assim, estes deram prosseguimento à ação, a fim de retirar do registro civil da criança o nome do falecido, bem como os seus próprios nomes, que constavam como avós paternos.

A oitiva das testemunhas de ambas as partes, deixaram claro o forte vínculo afetivo criado entre o falecido e a infante, uma vez que o mesmo, já sabendo da ausência de paternidade, eventualmente ainda deixava presentes e visitava a criança na escola, além de entrar em estado depressivo após a descobrir que a requerida não era sua filha.

Dessa maneira, a sentença de mérito quanto ao caso exposto foi no sentido de julgar improcedente o pedido inicial e manter o proponente como pai, pois o reconhecimento da filiação registral fora feito de maneira voluntária e de acordo com a lei 8.560/92 e o artigo 1.609 do Código Civil, tal forma de reconhecimento não está necessariamente ligado à origem biológica . Do mesmo modo, a jurisprudência à época afirmava prevalência do vínculo afetivo sobre o biológico, em respeito ao melhor interesse da criança. Além disso, na aludida sentença, ficou resguardado o direito da requerida de, quando completasse a maioridade civil, optar pela paternidade biológica ou socioafetiva, a critério próprio. Inconformados, os requerentes apresentaram recurso de apelação, alegando que a paternidade, ainda que socioafetiva, não poderia ser mantida quando fundada em erro.

No decorrer do processo, o Ministério Público pediu o sobrestamento do feito, uma vez que o tema objeto em questão estava em discussão em sede de repercussão geral perante o Supremo Tribunal Federal. Posto isso, após o debate da matéria pela Suprema Corte, restou fixada a aludida tese de repercussão geral n ${ }^{\circ} 622$, estabelecendo que a "A paternidade socioafetiva declarada ou não em registro público, não impede o reconhecimento do vínculo de filiação concomitante baseado na origem biológica, com efeitos jurídicos próprios". Assim, conforme mencionado, foi reconhecida a multiparentalidade, determinando a possibilidade de coexistência entre a filiação biológica e a socioafetiva, sem hierarquia entre si. De forma que foi extinta a obrigatoriedade de escolha entre uma delas.

Por conseguinte, no caso em tela, em 2018, os Desembargadores do Egrégio Tribunal de Justiça do Estado do Piauí decidiram, por unanimidade, negar provimento ao recurso apresentado e manter a sentença fustigada por suas próprias razões. 
Dessarte, é importante ressaltar que hodiernamente, não há o dever da requerida ter que escolher entre o pai socioafetivo ou o biológico, pois devido à referida tese de repercussão geral, a filha poderá contar com os "dois pais" no seu assento de nascimento.

Dessarte, resta patente afirmar que os vínculos afetivos, notoriamente após a tese de Repercussão Geral no 622 do Supremo Tribunal Federal, passam a dispor de especial proteção jurídica, vez que restou evidenciado a ausência de hierarquia entre as parentalidades biológica e socioafetiva.

Outrossim, merece destaque a possibilidade de reconhecimento extrajudicial da multiparentalidade. A matéria é regulada no Provimento $\mathrm{n}^{\circ} 63$ de 2017 do Conselho Nacional de Justiça. O art. 14, caput, do referido diploma legal preceitua que: “[...] somente poderá ser realizada de forma unilateral e não implicará o registro de mais de dois pais ou duas mães no campo FILIAÇÃO no assento de nascimento" (Provimento nº 63 de 14 de novembro, 2017).

Diante disso, segundo Tartuce (2020), haviam muitas dúvidas sobre ser possível ou não o reconhecimento extrajudicial da multiparentalidade, o que poderia ser aperfeiçoado trazendo mais clareza ao texto legal, de modo a dirimir os questionamentos que insurgiam.

Dessa maneira, sobreveio o Provimento ${ }^{\circ} 83$ de 2019 do CNJ, que trouxe algumas alterações pontuais no provimento anterior quanto ao reconhecimento extrajudicial da paternidade/maternidade socioafetiva, tais como, critério etário de pessoas acima de 12 de anos, bem como o consentimento deste, caso seja menor de 18 anos; vínculo estável e socialmente exteriorizado; comprovação da afetividade por todos os meios de prova admitidos em direito, além da necessidade de parecer favorável do Ministério Público (Provimento no 83 de 14 de agosto, 2019).

Outrora, foram acrescidos ao art. 14 do Provimento 63 do CNJ, dois novos parágrafos, embora o caput do referido artigo não tenha sofrido alteração, confirmando o registro da multiparentalidade em cartório, no entanto, limitando a apenas um ascendente socioafetivo. Caso haja pretensão de incluir mais de um ascendente, deve-se recorrer à via judicial (Tartuce, 2020).

Logo, diante do exposto, resta claro a possibilidade de reconhecimento extrajudicial, viabilizando assim, a existência da multiparentalidade unilateral, ou seja, limitada apenas a um ascendente sociafetivo, seja da linha paterna ou materna, desde que preenchidos os requisitos legais e obtenha parecer favorável do Parquet.

\subsection{Efeitos jurídicos da multiparentalidade}

Em decorrência da possibilidade de uma pessoa ter, ao mesmo tempo, dois pais e uma mãe, ou vice versa, resta claro, em decorrência da tese jurídica da Corte Excelsa, não havendo margem de dúvidas, de que serão gerados todos os efeitos jurídicos que decorrem de uma relação familiar, quais sejam, obrigação de prestar alimentos, direitos sucessórios, parentesco, poder familiar e direito à convivência (Farias \& Rosenvald, 2017).

Outrossim, em consonância com o entendimento ora exposto, o Enunciado no 9 do Instituto Brasileiro do Direito de Família (IBDFAM) dispõe que: "A multiparentalidade gera efeitos jurídicos”. Diante disso, podem ser elencados como repercussões oriundas do reconhecimento do referido instituto: direito ao nome, alimentos, guarda/visita, bem como os direitos sucessórios.

\subsubsection{Direito ao nome}

O direito ao nome encontra fulcro no art. 16 do Código Civil de 2002: "Toda pessoa tem direito ao nome, nele compreendidos o prenome e o sobrenome".

Atualmente, percebe-se que as relações interpessoais estão pautadas principalmente nos vínculos afetivos, surgindo assim um novo de conceber essa realidade, que deixa de ser estritamente identificada pela verdade biológica, o que acaba por 
refletir-se tantos nas questões conjugais como também no que concerne à perfilhação. Sendo assim, a filiação socioafetiva vem ganhando destaque no meio jurídico, trazendo implicações também na esfera do direito ao nome (Dias, 2021).

Conforme Farias e Rosenvald (2017), o registro civil deve refletir a pluralidade de vínculos parentais. Por conseguinte, isto implica na necessidade de constar no assento de nascimento o nome de todos os pais, bem como os respectivos sobrenomes, de modo a contemplar todos os vínculos ali formados.

Uma vez suscitada a ação de reconhecimento pelo ascendente biológico e ao mesmo tempo restando demonstrada a relação afetiva em relação ao pai registral, é possível figurar os sobrenomes dos referidos pais, bem como de todos os avós paternos, configurando-se no caso em comento a pluriparentalidade (Dias, 2021).

Dito isso, é evidente que tal direito é uma garantida conferida pelo ordenamento jurídico a fim de dar maior segurança aos que estão interligados ao instituto da multiparentalidade, sendo imprescindível aos envolvidos nessa relação. Ademais, trata-se de um direito personalíssimo, sendo inerente à existência do próprio ser humano.

\subsubsection{Direito aos alimentos}

O art. 1.694, caput, do Código Civil estabelece que: "Podem os parentes, os cônjuges ou companheiros pedir uns aos outros os alimentos de que necessitem para viver de modo compatível com sua condição social, inclusive para atender às necessidades de sua educação".

Tartuce (2020), afirma que o direito aos alimentos é personalíssimo, ou seja, possui caráter intuitu personae, visto que somente pessoas com vínculos de parentesco, casamento ou união estável poderão exigí-los.

É inegável afirmar que o dever de prestar alimentos encontra amparo legal em vários dispositivos do ordenamento jurídico pátrio, apresentando-se, por conseguinte, como um dos efeitos inerentes à filiação. Logo, surge uma discussão a respeito de como ficaria a referida obrigação levando-se em consideração o instituto da multiparentalidade.

Segundo Tartuce (2020), a multiparentalidade gera todos os efeitos jurídicos, incluindo os direitos alimentares, sendo plenamente possível o filho postular alimentos do pai biológico, juntamente com o socioafetivo.

Dias (2021) aduz que é possível fixar valores diferentes de pensão alimentícia a cada um dos pais sem gerar direito regressivo entre os vinculados. Isso é possível devido ao fato de não haver solidariedade entre eles na obrigação de pagar alimentos.

Em consonância com o exposto, como reflexo do princípio da dignidade da pessoa humana, os alimentos devem obedecer ao binômio necessidade-possibilidade. Outrossim, em regra, tal obrigação não será solidária, mas divisível. Dessa forma, mesmo não havendo entendimento pacificado, na multiparentalidade, os codevedores não são solidários entre si, sendo a obrigação de cada um deles fornecer os alimentos de acordo o binômio supramencionado, podendo ainda chamar os demais vinculados à lide (Siqueira \& Lima, 2020).

Frise-se, por oportuno, há reciprocidade entre pais e filhos no que concerne ao direito de prestação alimentícia (Lei nº 10.406 de 10 de janeiro, 2002). Nesse sentido, surge o questionamento se tal assertiva aplica-se em relação os múltiplos pais que vierem a pleitear os alimentos em face dos filhos, tidos como os principais favorecidos na relação multiparental. Segundo Santos (2018), a resposta parece ser positiva, podendo o bônus converter-se futuramente em um ônus, tendo em vista que não se pode deixar de prestar o auxílio necessário, sob pena de desvirtuar o próprio bojo do instituto, devido à solidariedade familiar. Ademais, outro questionamento suscitado diz respeito à cumulação de pensões pelo filho, porém inexiste vedação quanto a isso no direito brasileiro.

Conforme pode-se depreender diante dos posicionamentos retromencionados, parece não haver dúvida alguma de que o dever de prestar alimentos é de todos os envolvidos naquela relação, uma vez que não há qualquer espécie de distinção entre as parentalidades. 


\subsubsection{Direito de visita/companhia}

Segundo Cassettari (2015), podem ser encontradas decisões judiciais que versam sobre o direito de visita nas relações socioafetivas. De forma que é resguardado ao pai que não tiver a guarda do filho, o direito de visitá-lo e tê-lo em sua companhia, direito este que também é estendido aos avós socioafetivos enquanto durar o exercício do poder familiar. Entretanto, os horários, datas e frequências dessas visitas deverão ser acordados entre os cônjuges ou fixados pelo juiz.

A proteção da pessoa dos filhos está regulamentada dos artigos 1.583 ao 1.590 do Código Civil de 2002, preceituando que a guarda dos mesmos será unilateral ou compartilhada, de forma que a primeira é atribuída apenas a um dos genitores ou pessoa que o substitua, enquanto a última é exercida de forma conjunta pelo pai ou mãe que não vivam sobre o mesmo teto. Além disso, na guarda compartilhada o tempo de convívio estabelecido entre o pai e a mãe deve ser organizado de maneira harmoniosa, respeitando sempre o melhor interesse dos filhos, de modo que será considerada como moradia o local que melhor atender as necessidades destes.

Ademais, quando ambos os genitores quiserem e estiverem aptos a exercer a guarda, mas não houver acordo quanto a mesma será adotada a guarda compartilhada, de maneira que para determinar as atribuições de cada genitor, o juiz de ofício ou a requerimento do Ministério Público, poderá basear-se em orientação técnico-profissional ou equipe interdisciplinar, com a finalidade de estabelecer uma repartição equilibrada entre o tempo para cada um.

Sobre a possibilidade de guarda compartilhada dentro do instituto da multiparentalidade, Farias e Rosenvald (2017), preceituam que a parentalidade plúrima confere a todos os pais e/ou mães o direito de invocá-la, devendo haver, no entanto, a regulamentação da convivência, para que todos possam participar e cooperar de maneira efetiva na relação de filiação. Além disso, a possibilidade da guarda conjunta é reconhecida com o objetivo de possibilitar a melhor opção para o filho.

Destarte, as questões referentes à guarda, visitação e companhia serão sempre analisadas com base no princípio do melhor interesse da criança e do adolescente, buscando assim, a alternativa mais benéfica para os mesmos.

\subsubsection{Direitos sucessórios}

No que concerne à sucessão, na multiparentalidade, todas as regras sucessórias devem ser aplicadas aos parentes socioafetivos tal qual são aplicadas aos parentes biológicos, pois como já mencionado não há hierarquia, tampouco diferenciação, entre as paternidades.

É importante ressaltar que apesar de não usual que uma pessoa tenha direito a heranças de mais de dois ascendentes em primeiro grau, tal fato não vai de encontro à norma constitucional, ao contrário, reafirma a igualdade entre os filhos determinada na Constituição Federal, uma vez que a existência de dois, três ou mais vínculos parentais decorre de situações da vida (Schreiber \& Lustosa, 2016).

No mesmo sentido, preceitua o enunciado 33 do Instituto Brasileiro de Direito de Família (IBDFAM) que a filiação socioafetiva gera efeitos sucessórios, de forma que o filho é legítimo herdeiro, assim como os genitores e demais parentes, de forma recíproca, por direito próprio ou por representação.

No entanto, é necessário cautela quanto ao direito sucessório pleiteado post mortem, caso em que o autor já recebeu a herança dos pais registrais e nunca teve convivência com os pais biológicos, pois é imprescindível a construção da posse do estado de filho para que haja a construção desse direito (Cassettari, 2015).

Reprise-se que a posse do estado de filho é demonstrada por meio dos elementos evidenciados na convivência entre o pai e o rebento, que demonstrem o tratamento de ambos como tal, a repercussão social desse tratamento, e eventualmente o uso do nome do pai pelo filho, além a existência imprescindível do critério afetividade.

Assim, para evitar que a pluriparentalidade seja usada somente para efeitos sucessórios, necessário se faz a análise do caso concreto, observando a efetiva construção da posse do estado de filho, o preenchimento dos critérios necessários para o 
reconhecimento da parentalidade socioafetiva, bem como o estabelecimento de relação de afeto entre as partes.

No entanto, sobre as questões sucessórias ainda pairam algumas dúvidas, por exemplo, no que tange à situação fática em que o filho venha a falecer antes dos pais, pois se a multiparentalidade produz o efeito de que o descendente tenha direitos sucessórios em relação aos múltiplos pais ou mães, a recíproca também é verdadeira, de forma que os últimos também possuem direitos sucessórios em relação aos primeiros.

Entretanto, há uma celeuma em relação à forma que deverá ocorrer essa sucessão, pois o Código Civil vigente dispõe em seu artigo 1.836 que "os ascendentes da linha paterna herdam a metade, cabendo a outra metade aos da linha materna". Assim, a dúvida gira em torno se a herança seria dividida igualmente entre os múltiplos pais ou mães, ou se seria aplicada a regra do código civil, dividindo-a em duas partes iguais entre a linha materna e paterna, apesar de o primeiro entendimento ser o que mais se adequa ao princípio da isonomia entre os pais.

Outrossim, existem outras situações peculiares no que diz respeito a sucessão na multiparentalidade, quais sejam, a questão do quinhão dos herdeiros quando o filho morre deixando cônjuge e três pais, como também o caso deste falecer deixando apenas avós de três linhas parentais diversas (Schreiber \& Lustosa, 2016). Saliente-se que na primeira hipótese é aplicado o disposto no artigo 1.837 do Código Civil de 2002, preceituando que a herança será dividida em partes iguais entre o cônjuge e os três ascendentes, enquanto na última hipótese, reparte-se a herança por linhas, ou seja, metade para a linha materna e a outra para a linha paterna, seguindo o artigo 1.836 , $\S 2^{\circ}$ do referido Código Civil (Lei n 10.406 de 10 de janeiro, 2002).

Portanto, sobre os efeitos sucessórios produzidos pela pluriparentalidade socioafetiva, ainda existem alguns pontos a serem aperfeiçoados e analisados com cautela, tanto pelo legislador, produzindo normas que englobem a situação mencionada, quanto pelos aplicadores da lei, interpretando da melhor maneira possível as normas existentes enquanto regras específicas não são produzidas.

\section{Considerações Finais}

Hodiernamente é fato afirmar que as entidades familiares tem o afeto como alicerce. Dessa maneira, imperiosa se faz a necessidade de proteger e conferir tutela jurídica à família, em suas inúmeras constituições, visto ser ela a base da sociedade. Conforme expõe Dias (2021), o afeto passou a servir como indicador para definir os vínculos de parentesco.

Outrossim, sob a égide da Constitucionalização do Direito Civil, as relações privadas devem ser interpretadas conforme a Constituição. Como efeito, percebe-se que há uma preocupação maior voltada para a pessoa do ser humano, de modo a proteger sua dignidade, vindo esta a ser invocada como meio a justificar diversos direitos conferidos pelo ordenamento pátrio.

Insta salientar que muitas famílias brasileiras são caracterizadas pelo instituto da multiparentalidade, visto que é muito comum na sociedade o caso de famílias reconstituídas, em que os pais se separam e passam a vivenciar um novo relacionamento, em que as crianças e adolescentes começam a nutrir forte vínculo afetivo com o companheiro/cônjuge do pai ou da mãe, podendo ensejar uma pluralidade de vínculos. Lado outro, também há a possibilidade de que o filho venha a descobrir posteriormente que a pessoa que consta em seu registro civil, na realidade, não é seu ascendente genético, vindo a deparar-se com uma parentalidade por laços sanguíneos com outrem. $\mathrm{O}$ fato disso ocorrer não significa que a paternidade anterior, puramente socioafetiva, deve sucumbir. Pelo contrário, deverá ser protegida e tem igual valor jurídico da paternidade biológica, podendo ambas coexistirem.

Em 2016, o Supremo Tribunal Federal, como análise do Recurso Extraordinário nº 898.060, em que discutia-se possível prevalência de uma paternidade socioafetiva em face da paternidade biológica, entendeu por fixar a tese alhures mencionada, com o escopo de evidenciar, de uma vez por todas, que não há qualquer grau de hierarquia entre as paternidades, 
tanto é que a parentalidade socioafetiva e a biológica, podem subsistir paralelamente, de modo a assegurar o melhor interesse da criança ou adolescente.

Resta claro que a referida tese gera diversas repercussões jurídicas, dentre as quais podem ser citadas o direito ao nome, alimentos, guarda/visita, direitos sucessórios. Enfim, são diversas as consequências oriundas do entendimento da Corte, importando mencionar, por oportuno, que a doutrina tem desempenhado papel de destaque na interpretação de tais efeitos jurídicos, vez que se trata de um tema recente e que não há regramento próprio para regulamentar especificamente cada caso, de modo a tutelar da melhor maneira possível essa multiplicidade de vínculos.

Vale ressaltar que esse tema ainda deve ser bastante discutido na comunidade científica, sendo esse trabalho uma contribuição para futuras pesquisas, pois devida a importância desse objeto de estudo é necessária a ampliação do conhecimento sobre a multiparentalidade no âmbito jurídico brasileiro.

\section{Referências}

Apelação Cível n.2015.0001. 002753-7 (2018, 14 de agosto). Tribunal de Justiça do Estado do Piauí. Relator: Des. Raimundo Nonato da Costa Alencar. http://www.tjpi.jus.br/e-tjpi/home/jurisprudencia/buscar/pc.

Brasil. (1916). Lei $\mathrm{N}^{\mathrm{o}} 3.071$, de $1^{\circ}$ de janeiro de $1916 . \quad$ Código Civil dos Estados Unidos do Brasil de 1916. http://www.planalto.gov.br/ccivil_03/leis/13071.htm

Brasil. (2002). Lei $\mathrm{n} 10.406$ de 10 de janeiro de 2002. Lei de Introdução às Normas do Direito Brasileiro. http://www.planalto.gov.br/ccivil_03/leis/2002/110406compilada.htm.

Calderon, L. C. (2018). Multiparentaidade: A Socioafetiidade nos Laços de Filiação. Revista Jurídica da Escola Superior de Advocacia da OAB-PR, 2, 1-35. http://revistajuridica.esa.oabpr.org.br/wp-content/uploads/2018/09/revista_esa_06.pdf .

Cassettari, C. (2015). Multiparentalidade e Parentalidade Socioafetiva: efeitos jurídicos (2a ed.). Atlas.

Constituição da República Federativa do Brasil de 1988 (1998). http://www.planalto.gov.br/ccivil_03/constituicao/constituicao.htm

Dias, M. B. (2021). Manual de Direito das Famílias. (14a ed.). JusPodivm.

Enunciado 339 do CJF/STJ. IV Jornada de Direito Civil. Conselho da Justiça Federal. https://www.cjf.jus.br/enunciados/enunciado/369

Enunciados do IBDFAM. IBDFAM.. https://www.ibdfam.org.br/conheca-o-ibdfam/enunciados-ibdfam.

Farias, C. C. \& Rosenvald, N.(2017). Curso de Direito Civil: famílias. (9a ed.). JusPodivm.

Farias, C. C. \& Rosenvald, N. (2018). Curso de Direito Civil: famílias. (10a ed.). JusPodivm.

Gagliano, P. S. \& Filho, R. P. (2017). Novo curso de direito civil: direito de família. (7a ed.). Saraiva.

Gagliano, P. S. \& Filho, R. P. 2019). Novo curso de direito civil: direito de família. (9a ed.). Saraiva.

Gil, A. C. (2010). Como Elaborar Projetos de Pesquisa. (5a ed.). Atlas.

Gonçalves, C. R. (2017). Direito Civil Brasileiro: direito de família.(14a ed.). Saraiva.

Gutierrez, J. P., Rocha, T. d., \& Ferrão, A. S. (2011). O afeto como principal vínculo familiar e sua abordagem no direito de família brasileiro. Revista Videre, 171-198. https://ojs.ufgd.edu.br/index.php/videre/article/view/1060.

Marconi, M. d., \& Lakatos, E. M. (2019). Fundamentos da Metodologia Científica. (8a ed.). Atlas.

Noronha, M. M., \& Parron, S. F. (2012). A evolução do conceito de família. Revista Pitágoras, 1-21. http://uniesp.edu.br/sites/_biblioteca/revistas/20170602115104.pdf.

Pereira, R. d. (2016). Princípios fundamentais norteadores do direito de família. (3a ed.). São Paulo: Saraiva.

Provimento $\mathrm{n}^{\mathrm{o}} 63 \quad(2017,14$ de novembro). Conselho Nacional de justiça. https://atos.cnj.jus.br/files//provimento/provimento_ 63_14112017_19032018150944.pdf.

Provimento $\mathrm{n}^{\mathrm{o}} 83$ (2019, 14 de agosto). Conselho Nacional de justiça. https://atos.cnj.jus.br/files//provimento/provimento_63_141 12017_19032018150944.pdf.

Recurso Extraordinário 898.060 SC (2016, 22 de setembro). Supremo Tribunal Federal. Relator: Ministro Luiz Fux. http://www.stf.jus.br/portal/jurisprudenciarepercussao/verAndamentoProcesso.asp? incidente $=4803092 \&$ numeroPro cesso $=898060 \& \mathrm{classeProcesso}=\mathrm{RE} \& \mathrm{num}$ eroTema $=622 \#$. 
Research, Society and Development, v. 10, n. 9, e4610917629, 2021

(CC BY 4.0) | ISSN 2525-3409 | DOI: http://dx.doi.org/10.33448/rsd-v10i9.17629

Rosa, C. P. (2020). Direito de família contemporâneo.(7a ed.). JusPodivm.

Santos, G. P. (2018). Multiparentalidade e seus efeitos em relação aos alimentos: da dogmática à efetividade. https://www.acervodigital.ufpr.br/handle/1884/62672.

Schreiber, A. (2020). Manual de direito civil contemporâneo. (3a ed.). Saraiva Educação.

Schreiber, A., \& Lustosa, P. (2016). Efeitos jurídicos da multiparentalidade. Revista Fortaleza Pensar, 847-873. https://web.bndes.gov.br/bib/jspui/bitst ream/1408/16480/1/PRArt214244_Efeitos\%20jur\%c3\%addicos\%20da\%20multiparentalidade_compl_P_BD.pdf.

Siqueira, D. P., \& Lima, H. F. (2020). Multiparentalidade e a efetividade do direito da personalidade aos alimentos: Uma análise a partir da visão do Supremo Tribunal Federal n. RE 898.060. Revista Direito em debate, 246-259. 10.21527/2176-6622.2020.54.246-259. https://revistas.unijui.edu.br /index.php/revistadireitoemdebate/article/view/9302.

Tartuce, F. (2020). Manual de direito civil: volume único. (10a ed.). Forense; Método.

Xavier, F. D. (2015). União Estável e Casamento: a impossibilidade de equiparação à luz dos princípios da igualdade e da liberdade. https://www.tjdft.jus.br/institucional/escola-de-administracao-judiciaria/copy_of_e-books/e-books-pdf/uniao-estavel-e-casamento. 